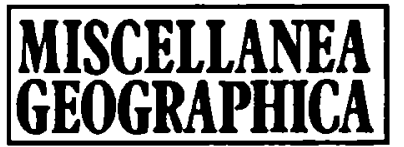

WARSZAWA 1996 Vol. 7

Florian Plit

\title{
DESERTIFICATION ON SAHARA BORDERS AND IN CENTRAL ASIA - COMPARATIVE STUDY
}

Elaboration of regional comparative studies of the factors, mechanisms and effects of desertification is considered today as one of the most important research works. It is obvious that these studies could be a transitory stage from detailed regional and local studies to the attempts of global synthesis. Such a synthesis seems to be impossible at present. It is so because of nearly complete lack of reliable informations on desertification of the vast Asian territories in Iran, Afghanistan and in the borders of Pakistan and India, in west China and Tibet and also inside the Arab Peninsula. Although it is very well known that the desertification processes are growing in these regions to nearly catastrophic proportions, it is, however, impossible to gain any detailed reports on the issue. Such comparative studies were recommended by UN Conference in Nairobi, and in the initial stage UNESCO played special role in coordinating these studies (see for example J.A. Mabbutt, C. Floret, 1980) but in more recent time FAO is taking more significant part in this field.

Complexity of the problems involved is the most important reason of scarcity of comparative studies sensu stricto, as in most cases we have to deal with a set of several regional studies. There are few exceptions such as: L.A. Dorokhov's study (1983) of Australian and Central Asian deserts (being merely limited to physical geography) and J.-H. Durand's study (1988) devoted to both northern and southern Sahara borders (emphasising almost exclusively methods of combating desertification and only marginally its reasons).

In this study we compare desertification processes in three regions namely southern Sahara border (Sahel) and its northern border, and in former Soviet Central Asia. These regions are different in many aspects but they share one of them, i.e. they were considered - though in different times - as the most endangered by desertification processes (and in general by environmental degradation) as compared with the whole world. We give here the summary of a more widely elaborated study (F. Plit, 1995) based on references and random studies performed in the area. 
It is known that in each of these regions the vehement increase of desertification processes once took place. This was most obvious in Sahel region during the great drought in 1968-1973, also powerful intensification of those processes was observed in Algeria during the several years after gaining independence; also in Central Asia in eighties when Aral Sea level dropped considerably and negative effects of this phenomenon were seen. Both on the borders of Sahara and in Central Asia it was not a sudden and unexpectable ecological disaster but only an intensification of the earlier ongoing processes. In those three regions there was a significant population increase in the second part of twentieth century. The increase was bigger than the average increase of world population and took place at the same rate in each of these regions that is illustrated in Figure 1.

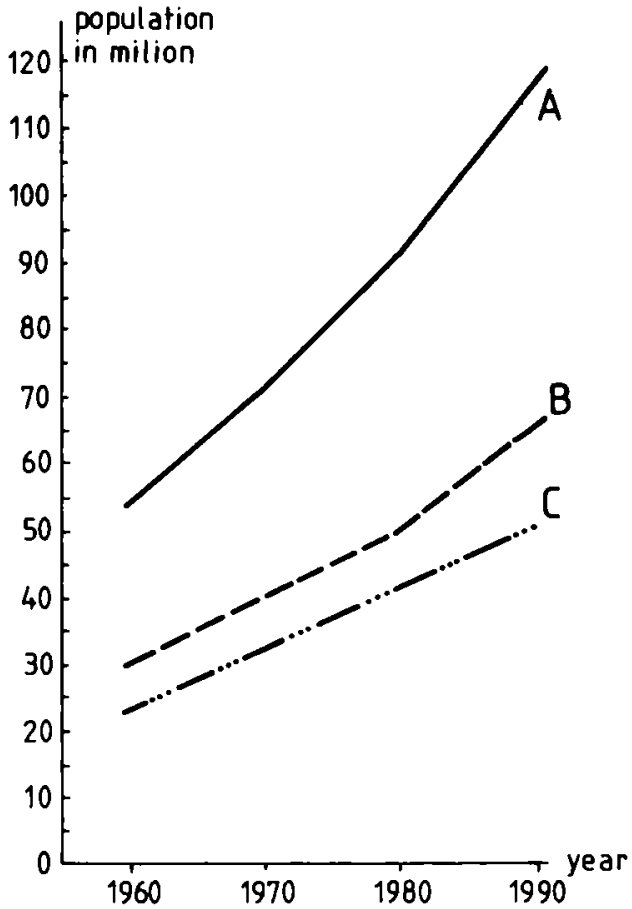

a)

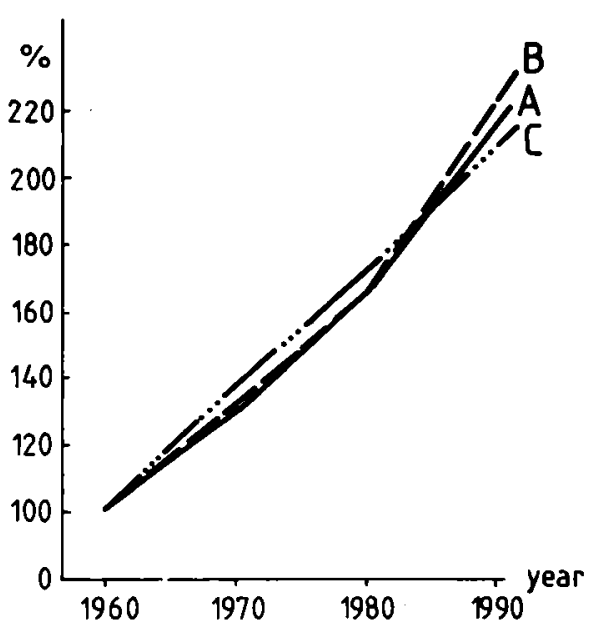

b)

Fig. 1. Population increase in Sahara borders and Central Asia (according to different statistic annuals): diagram a - in absolute numbers, diagram b - in relative numbers: $1960=100 \%$. A - northern Sahara borders: Morocco, Algeria, Tunisia, Libya, Egypt, B - southern Sahara borders: Mauritania, Senegal, Mali, Niger, Burkina Faso, Chad, Sudan, C - Central Asia Kazakhstan, Turkmenistan, Uzbekistan, Tadzhikistan, Kirgizia. It is well seen on diagram b that the population increase rate is almost the same in all three regions

In demographic respect Central Asia was considered as a typical Third World region in twentieth century. Perhaps this was influenced to great extend by Islam religion and Muslim family model that made the increase of population in Uzbekistan or in Turkmenistan quicker and bigger in al- 
most each case than in Kazakhstan, despite the fact that a lot of people were sent into exile to this later. On both northern and southern Sahara borders demographic explosion could be considered as a main though indirect reason of desertification. In both regions extensive agricultural policy didn't change substantially in this period of time, so the increase in population has led to the increase in animal breeding and farming areas (see Fig. 2).

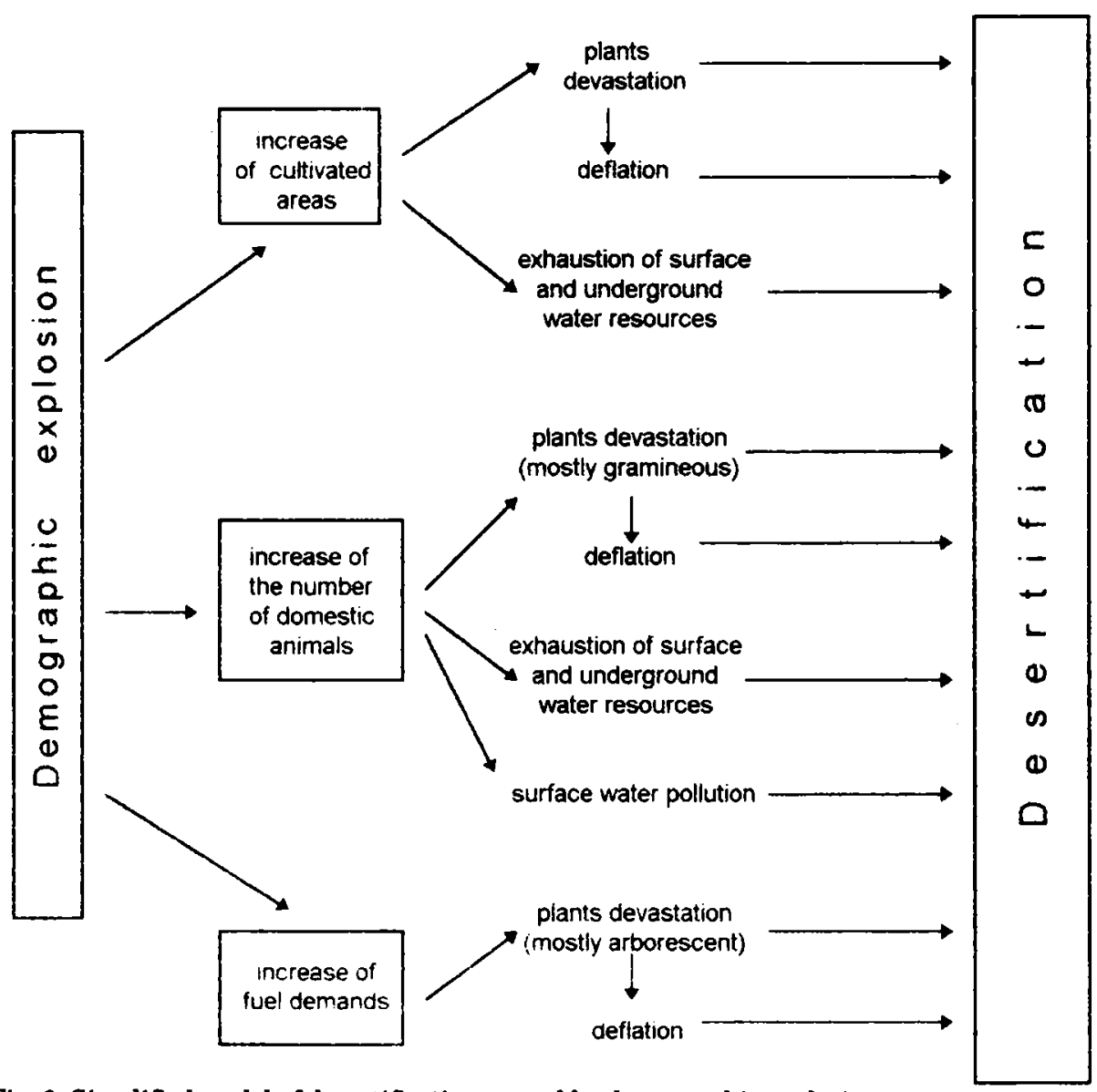

Fig. 2. Simplified model of desertification caused by demographic explosion

The regions where animal breeding was on the same level were exceptional (for example in Morocco).

Along with the population increase desertification could be observed in connection with plants exploitation for fuel. In Central Asia there were not such simple relations between the population increase and desertification as it was in the case of Sahara borders. Until quite lately the central systems of the cultivated area increase and domestic animals control were in force there. According to statistics the number of domestic animals has 
been on the same level since several years. In studies on this subject of desertification the attention is not paid to possible relations between the process of natural environment degradation in Central Asia and the population increase. It seems, however, that if such studies were performed to a local scale in isolated and difficult to access territories where Haloxylon tree has been still used for fuel, the results would be similar to those of Sahara borders. On the all Central Asia scale it is necessary to connect demographic explosion - at least in indirect way - with the great increase of areas artificially irrigated which is one of the most important factors of desertification in the region.

Limitation of the population increase should be considered as a prerequisite to check desertification processes on Sahara borders, and perhaps in Central Asia. Taking into account Muslim traditions in all the above mentioned regions it would be extremely difficult task. Moreover it should be considered that the renaissance of Islam religion in Central Asia could be followed by speeding-up of environmental degradation processes in the region. Such a phenomenon was observed in Algeria immediately after gaining independence, where the rapid increase of the number of sheep took place. In Central Asia where birth rate is very high and where the local authorities are boosting national traditions of shepherd-nomadic model of life and fundamentalist groups are emerging, and in the same time central domestic animal herds control ceases, so the results of ongoing transformations could be disastrous for local environment. The intense programs of arid and semi-arid lands cultivation aimed at changing of the conditions of natural environment should be blamed as one of the main reasons of desertification. They were taking into account only temporary benefits without regarding long term outcome. Such approaches are evident in Central Asia first of all where artificial irrigation systems in certain regions have led to considerable decay of other lands, also in Sahel where acceleration of desertification processes followed abyssal wells drilling. On northern Sahara borders there were not such obvious and ill-considered cases of human intrusion in natural environment, so the process of desertification was considerably limited and mostly related to establishing of shepherds cooperatives.

Particular cases of desertification closely related to the programs of arid and semi-arid lands cultivation are those of industrial origin, i.e. direct result of soil destruction by heavy machines and equipment in building areas or in the route of transportation cross-country running highways. Such damages were seen especially in Central Asia, in connection with powerful technical potential of the former USSR as well as with the typical communist impetus in accomplishing of investments without taking into consideration the full range of natural conditions and spatial limitations. In North Africa this kind of technological desertification is less extensive and rarely referred to in references. However, we are witnessing today - though on limited scale - new patterns of 
technological desertification (for example in connection with car rallies) that could be destructive in the future.

The desertification processes usually get stronger in the periods of political and social transformation. In those instants it is not clear who is really in power, the regional authorities fail to be reliable and all the mechanisms of public control get distracted to the extend that nobody is responsible for exploitation and protection of natural environmental resources. It is not by chance that the increase of natural environmental degradation became more spectacular in the first few years after gaining independence in African countries. In Algeria for instance where there were strong tendencies to force "socialistic option" after gaining independence and the changes were exceptionally wide, the degradation of natural environment became extraordinary strong. In Central Asia countries in the last few years of Soviet Union existence and the communist power here faced serious crisis, we could observe the lesion struggle against desertification (i.e. sand-drift fixing and planting trees).

Although the profound political and economical transformations often stimulate desertification processes, it should be noticed at the same time that the deep structural and political and social changes are the main condition for successful struggle against desertification. It is especially referred to the necessity of legal definition of ownership. In all the three above mentioned regions the desertification processes became especially visible in those territories that belonged to nobody, i.e. in nationalized Algerian steppe, on Moroccan grasslands on which the right of pasturage had been given to all the tribes driving herds of animals there and back; around those water wells in Sahel, to which shepherds from different regions were given free access; in collective farms in Central Asia, where water, plough lands, grass lands and herds were nationalized, i.e. it had become nobody's property. It is not necessary obvious that determining an owner of a land prevents it from being deserted but it often makes the basis for proper utilization of the grounds.

The necessity of determining ownership right is applied not only to land but first and foremost to water sources that constitute the most valuable substance on arid and semi-arid lands.

Similarities and differences in the processes of desertification on the three above mentioned regions could be illustrated by regional desertification models. In Sahel (Fig. 3) the "traditional" factors of desertification still play the most important role being connected with demographic explosion: the increase of farming lands, the number of domestic animals and fuel demands. This model includes all the elements derived from models of desertification caused by demographic explosion. In addition this desertification becomes greater in effect of the settlement of nomadic peoples. All those factors included in the model should be considered as the main reasons of desertification. 


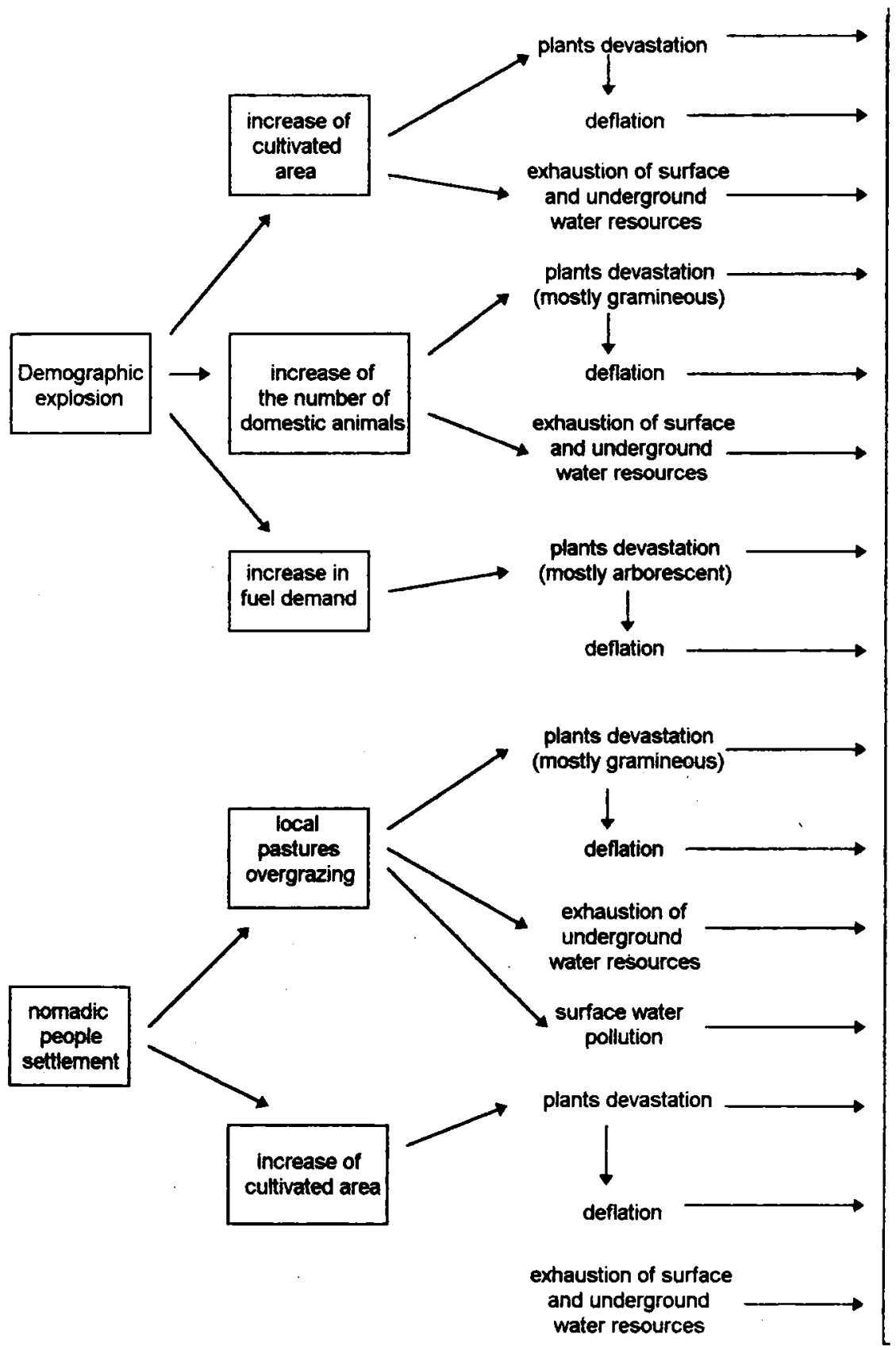

Fig. 3. Anthropogenic desertification model in Sahel region 


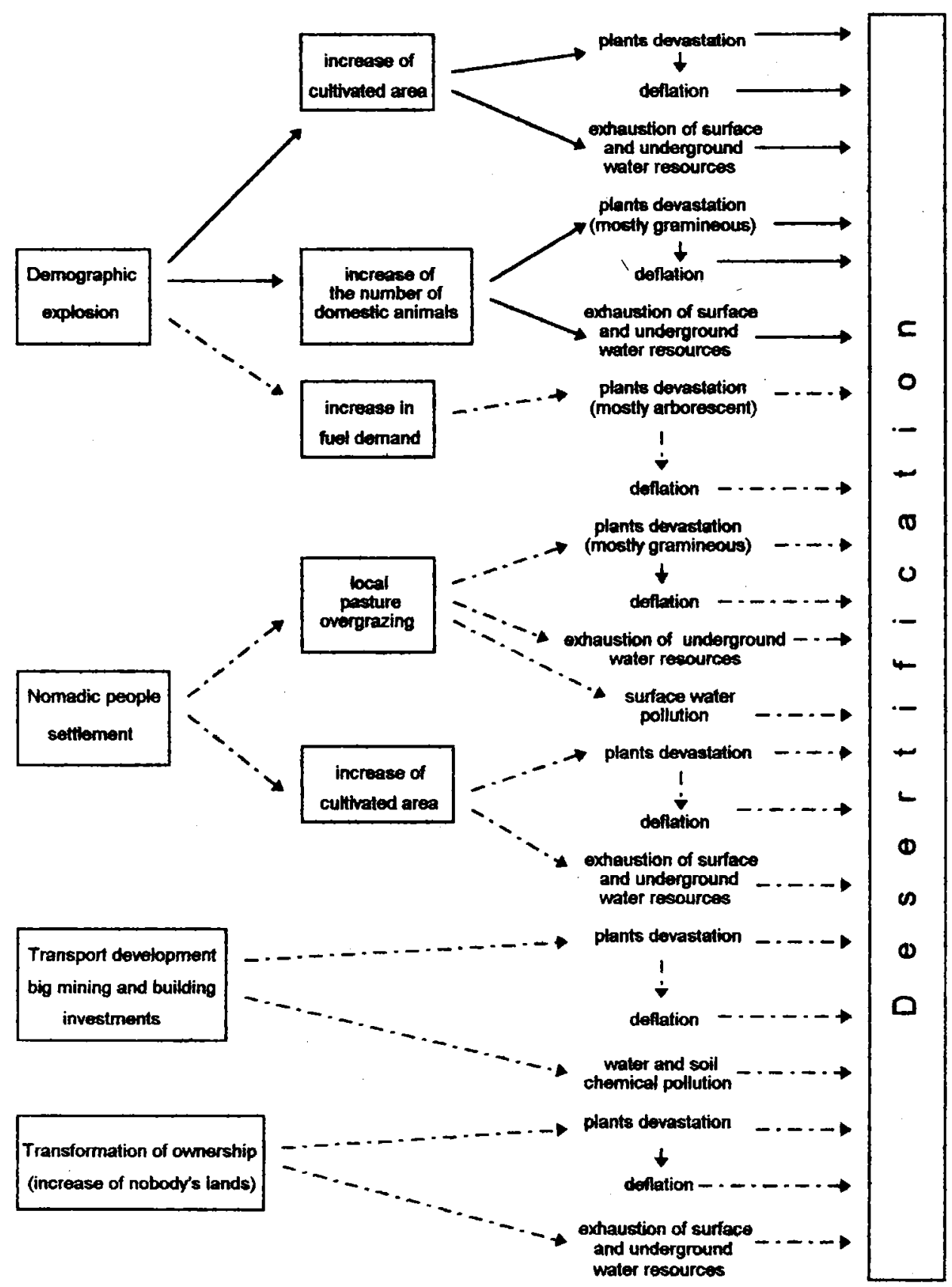

Fig. 4. Anthropogenic desertification model in northern Sahara borders $(\rightarrow$ main desertification processes, $\rightarrow$ secondary desertification processes) 


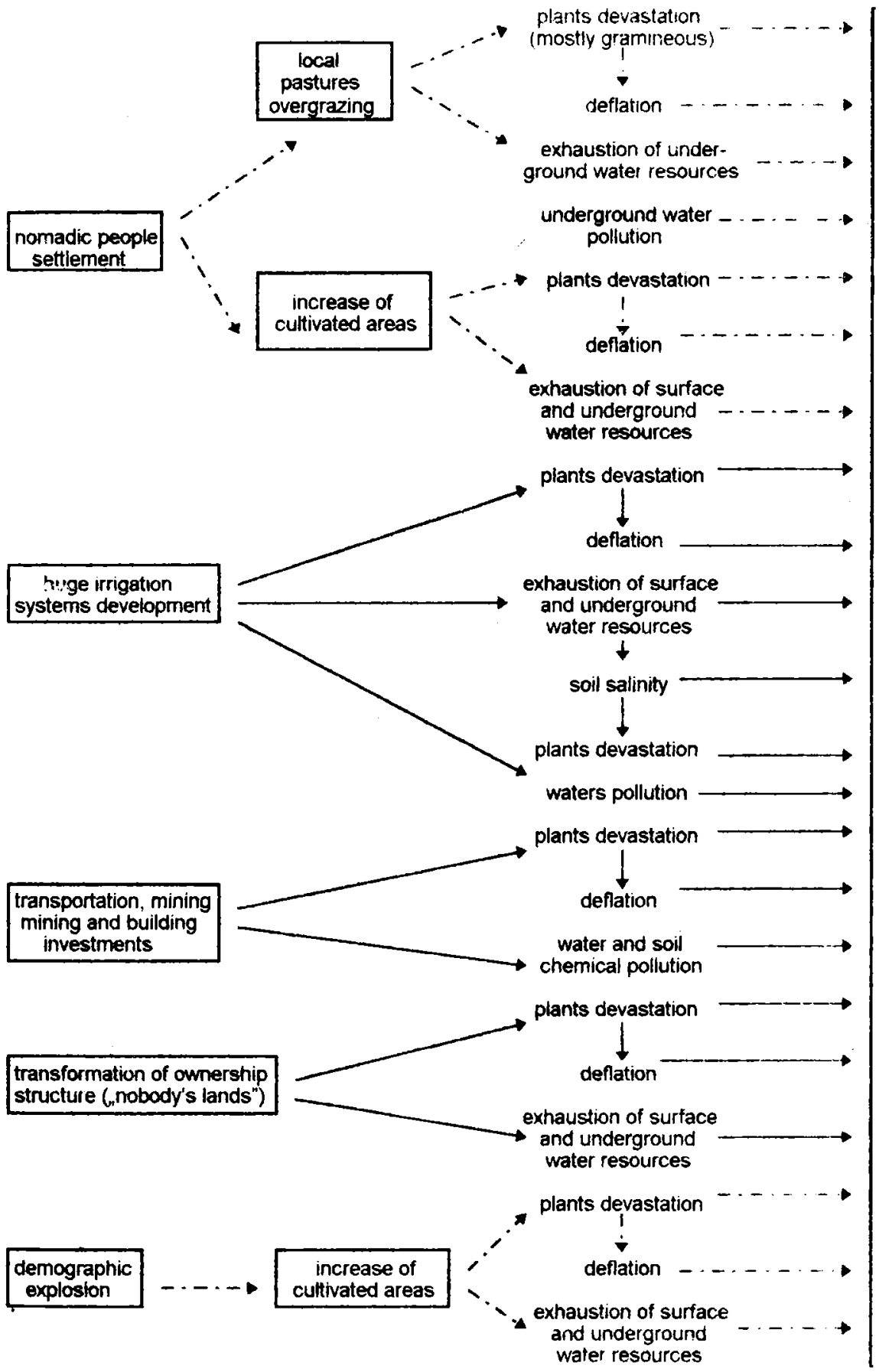

Fig. 5. Anthropogenic desertification model in Central Asia $(\rightarrow$ main desertification pr .... secondary desertification processes) 
The situation is more complex in the northern Sahara borders (Fig. 4) The demographic explosion is to a great degree the main reason of desertification first of all as a result of the increase of cultivated lands and the number of domestic animals. Fuel demand is one of the factors indeed but it is of less importance and could be regarded as the secondary one. In northern Sahara borders influences of factors of desertification could be observed in connection with modern economy and arid and semi-arid lands cultivation, and settlement of nomadic tribes, also mining industry development and transformation of legal ownership. However, these factors are of less importance and could be regarded as secondary ones.

In Central Asia (Fig. 5) the processes of desertification connected with modern economy application and utilization of arid and semi-arid lands predominate decidedly. There are several factors causing desertification in this region: development of irrigation systems, transformation of ownership structures and development of transportation roads and huge investments carried out there.

However, there is a lack of reliable informations of the ecological output of nomadic people's settlement that makes us recognize this factor as the secondary one at least, and even question it at all. It is rather supposition that this process influences desertification processes in Central Asia.

Among other factors of desertification process caused by demographic explosion in Central Asia the increase of cultivated land's area has its great influence. It is closely related to the development and intensification of irrigation systems. However, taking into account the fact that demographic explosion has had very weak influence in decision making process in this matter we consider it as a secondary factor.

\section{REFERENCES}

Do rok hov L.A., 1983, Australia Deserts and its parity in Central Asia (in Russian), Ylym, Ashkhabad.

D u r a n d J.H., 1988, Arrêter le désert, Paris.

Plit F., 1995, Pustynnienie antropogeniczne na obrzeżach Sahary $i$ w Azji Środkowej. Studium porównawcze (Anthropogenic desertification in Sahara borders and in Central Asia. Comparative studies), Warszawa.

$\mathrm{M}$ a b b u t t J.A., F l o ret C., 1980, Case studies on desertification, UNESCO, Paris. 
